\title{
T Cell Receptor Variable Regions in Diabetes Bind to Each Other, to Insulin, Glucagon or Insulin Receptor, and to Their Antibodies
}

\author{
Robert Root-Bernstein ${ }^{* 1}$ and Abigail Podufaly ${ }^{2}$ \\ ${ }^{1}$ Department of Physiology, 2174 Biomedical and Physical Sciences Building, Michigan State University, East Lansing, \\ MI 48824 USA \\ ${ }^{2}$ College of Human Medicine, Michigan State University, East Lansing, MI 48824 USA
}

\begin{abstract}
Our objective is to elucidate the nature of the autoimmune disregulation in diabetes through the antigen specificity of the T-cell receptor (TCR) sequences generated by patients with type 1 diabetes mellitus (T1DM). Previously we demonstrated that TCR from T1DM patients and NOD mice mimic insulin, glucagon and their receptors. We hypothesize that these TCR will bind to each other (as insulin and glucagon do to their receptors) and also be targets of anti-insulin and anti-glucagon antibodies. The hypervariable regions of multiple TCR from three patients were synthesized and their binding specificities determined using UV spectroscopy. ELISA was used to determine whether these TCR were recognized by anti-insulin and anti-glucagon antibodies. Each patient produced TCR that recognized insulin, glucagon and the insulin receptor (IR). These TCR also recognized each other as complementary (possibly idiotype-antiidiotype) pairs. In addition, each TCR peptide was recognized with nanomolar affinity as an antigen by an antibody against insulin, glucagon, and/or IR. Finally, each of the antibodies against insulin, glucagon and IR formed a complementary antibody (or idiotype-antiidiotype) pair with another antibody involved in the disease, again at nanomolar affinities. Every possible expression of complementarity (or idiotype-antiidiotype cross-reactivity) involving TCRs and antibodies was manifested by each patient. Two interpretations of these observations are offered. One, following Marchelonis, is that TCR-antibody complementarity is a mechanism for down-regulating the autoimmune process to re-establish tolerance to self-antigens. A non-exclusive alternative is that the trigger for autoimmunity is antigenic complementarity, which results in the production of complementary TCR and antibodies that appear to have idiotype-antiidiotype relationships among themselves.
\end{abstract}

Keywords: T-cell receptor cross-reactivity, TCR-TCR antiidiotypy, antibody-TCR antiidiotypy, antibody-antibody antiidiotypy, diabetes, islet cell antigen, PTP-IA-2, insulin, insulin receptor, glucagon, glucagon receptor, insulin antibody, insulin receptor antibody, glucagon antibody, antigenic complementarity, complementary antigens, complementary antibodies, complementary TCR, complementary BCR, molecular mimicry.

\section{INTRODUCTION}

Insulin is a major target of the autoimmunity involved in type 1 diabetes mellitus (T1DM) [1-9] as is the islet cell antigen 512 (receptor-type tyrosine protein phosphatase-like $\mathrm{N}$ protein, PTP-IA-2) [10-13] and in many cases the insulin receptor [14-18]. The cause and nature of the immune disregulation that results from the targeting of insulin and isletcell antigens is still mysterious. One clue may reside in the specificity of the $\mathrm{T}$ cell receptors (TCR) generated during the disease. The hypervariable $(\mathrm{V} / \mathrm{D} / \mathrm{J} ß)$ regions of T-cell receptors (TCR) from patients with T1DM and from the NOD mouse model of diabetes have been sequenced previously by several investigators [4, 19-24]. The majority of these human diabetic and NOD mouse TCR sequences mimic insulin, glucagon, or their receptors (a selection of these is summarized here in Table 1) [25]. These observations

*Address correspondence to this author at the Department of Physiology, 2174 Biomedical and Physical Sciences Building, Michigan State University, East Lansing, MI 48824 USA; Tel: 517-884-5039;

Fax 517-355-5125; E-mail: rootbern@msu.edu suggest a series of surprising consequences that could have serious immunological implications for diabetics.

Since insulin is complementary to its receptor, and glucagon to its receptor, some diabetic TCR may correspondingly be complementary to each other and might therefore bind to each other as they would to antigenic targets. In other words, these TCR might act like idiotype-antiidiotype pairs. Other complementarities have also been reported. The insulin receptor has multiple regions that mimic insulin and glucagon, and the glucagon receptor has multiple regions that mimic glucagon and insulin [26-28], so that these receptors might also be targets of diabetic TCR. In addition, insulin and glucagon are complementary to each other and produce primary antibodies that are complementary, and so act like idiotype-antiidiotype pairs [29]. In consequence, TCR against insulin and glucagon might also be complementary to each other, and appear to act like idiotype-antiidiotype pairs. Patients with diabetes are also characterized by having antibodies against insulin [1-9], the insulin receptor [14-18] and to glucagon [30-31], so that these antibodies may target TCR mimicking insulin and glucagon or their receptors (Fig. 1). 


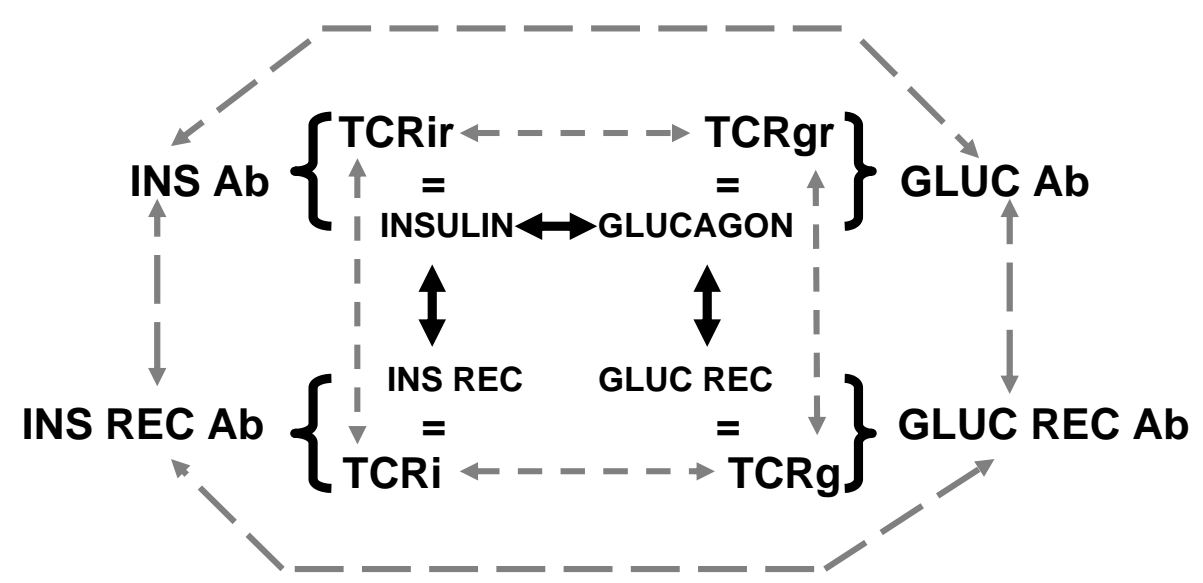

Fig. (1). Possible interactions between Figure Captions.

TCR and antigens in T1DM. Graphic illustration of known (black lines) and posited (gray lines) complementarities that exist between insulin, glucagon, their receptors; antibodies against these hormones and their receptors; and TCR sequences from T1DM patients. Insulin is complementary to its receptor, as is glucagon to its receptor. Antibodies to each hormone and each receptor are also complementary. In addition, insulin is complementary to glucagon so that the two hormones bind to each other and their antibodies are complementary so they act like an idiotype-antiidiotype pair [29]. The situation is complicated by the fact that the insulin receptor contains multiple regions that mimic insulin itself, and these insulin-like regions are associated with insulin binding [26-28]. Similarly, the glucagon receptor has glucagon-like sequences that appear in glucagon-binding regions of the receptor [26-27]. Thus, it can be predicted that antibody against insulin may bind to the insulin receptor and that antibody against glucagon may bind to the glucagon receptor (dotted gray lines). The set of possible antigenic cross-reactions is further complicated by the fact that, as described in Table 1, the TCR from T1DM patients used in this study are similar to insulin (TCRi), glucagon (TCRg), insulin receptor (TCR ir) or glucagon receptor (TCRgr), which is indicated by the equals signs [25, 29]. In consequence, it is possible that: 1) TCR within a T1DM patient bind directly to insulin, glucagon, and/or their receptors (dotted gray lines); 2) that these TCR mimic the binding affinities of insulin, glucagon, and/or their receptors by binding to each other, i.e., they are complementary and act like idiotype-antiidiotype pairs (dotted gray lines); 3) that antibodies against insulin, glucagon and their receptors will recognize the TCR that mimic these peptides and proteins (dotted gray lines); and 4) that the antibodies against insulin, glucagon, and their receptors will interact in all their possible combinations to produce a network of idiotype-antiidiotype pairs (dotted gray lines). In sum, the sets of complementarities found among the hormones and their receptors may be mimicked by the sets of complementarities found among the TCR that mimic them and antibody reactivity to these TCR. Such complementarities should be reflected in multiple types of cross-reactivity and complementary networks within individual T1DM patients. Note that the islet cell antigen 512 (PTP-IA-2), which is known to be a target of autoimmunity in T1DM [10-13] is highly homologous to insulin and the insulin receptor (Table 1), so that TCR are also likely to recognize it as an antigen. PTP-IA-2 may therefore be substituted in each place that insulin and insulin receptor appear in this diagram as a means of making predictions about its cross-reactivities with T1DM-generated TCR. See also Figs 7C and 7D.

And finally, we demonstrate here that the islet cell autoantigen PTP-IA-2 [10-13] has significant homologies to both insulin and to the insulin receptor (Table 1) so that the various cross-reactivities described above for insulin and the insulin receptor may also apply to PTP-IA-2. These predictions would extend the concept of a network of complementary interactions (perhaps described by an idiotypeantiidiotype network) to interactions not only between antibodies, but also between pairs of TCRs as well as between antibody-TCR pairs in diabetes. The purpose of this paper is to report the results of experimental tests of these possibilities.

\section{MATERIALS AND METHODS}

\section{Homology Searches}

A search for possible homologies between human insulin (P01308), the insulin receptor (P06213), and PTP-IA-2 (islet cell antigen 512) (Q16849) was carried out at http://www.expasy.ch using LALIGN [32] using PAM250 and BLOSUM 80 search algorithms with gap penalties set on default parameters. Significance of homologies was determined by two criteria: at least 5 identities in a stretch of 10 amino acids and/or an E value greater than 35 (a measure of the probability of $\mathrm{p}<0.01$ that equivalent homologies would be found in a random search of 10,000 protein sequences of equivalent length). The comparison of the insulin receptor with PTP-IA-2 was carried out in two ways: 1) using the entire insulin receptor sequence and 2) using two specific sequences from the insulin receptor that have been identified as insulin-binding regions [28] (see Table $\mathbf{1}$ for sequences). These two insulin receptor peptides ), IR 105118 and IR 897-915 (SwissProt numbering from P06213), were synthesized and purified to at least $98 \%$ purity by the Mass Spectroscopy, Synthesis and Sequencing Facility of the Department of Biochemistry of Michigan State University and used as part of the studies described below to determine TCR affinity.

\section{Synthesis of TCR sequences}

Eight hypervariable V $\beta$ regions from TCR of three T1DM patients and seven hypervariable V $\beta$ from TCR of patients infected with HIV were synthesized and purified to at least $98 \%$ purity by the Mass Spectroscopy, Synthesis and Sequencing Facility of the Department of Biochemistry of Michigan State University (Table 2). The eight diabetic TCR were chosen because they represented at least three different 
Table 1. Homologies between Insulin or Insulin Receptor Peptides and PTP-IA-2 (Islet Cell Antigen 512). PTP-IA-2 is a Major Target of Autoimmunity in T1DM. It has Many Significant Homologies with Insulin (see Table 2) and with the Two Insulin Receptor Peptides (95-113 and 897-916) that were Tested for Recognition by TCR (See Tables 1 and 4). Because of these Multiple Homologies, it is Likely that at Least Some of the TCR that Recognize Insulin and IR Peptides Will Recognize PTP-IA-2 as Well. Notably, Honeyman, et al. [13] have Demonstrated that Patients with T1DM Produce TCR Reactive to Several Cytoplasmic Regions of PTP-IA-2, in Particular 847-856 and 941-959, Both of which Appear in this Table. Honeyman, et al.[13] did not, however, test any of the Extracellular Regions of the Protein, which Encompasses Amino Acids 35-575, in which most of the Homologies Listed in this Table Appear. Further Research into these Homologies is Therefore Warranted

PTP-IA-2 951-959 (Q16849)
Insulin Receptor 95-113 (P06212)
PTP-IA-2 941-952 (Q16849)
PTP-IA-2 598-615 (Q16849)
Insulin Receptor 897-916 (P06212)

PTP-IA-2 110-117 (Q16849)

\author{
GLVRSKDQF \\ GLESLKD LFPNLTVIRGSR \\ I : : 1:1 1 \\ LEHVRDQRPGL
}

LCV- RQHARQQDKERLAAL

I 11 1:11: : | | :1

HLCVSRKHFA L ERGCRLRGL

MER I PRLR

PTP-IA-2 16-59 (Q16849) LRLLLCLLLLSSRPGGCSAVSAHGCLFDRRLCSHL -EVC IQDGLF

Insulin 5-49 (P01308) MRLLPLLALLALWGPDPAAAFVNQHLCGSHLVEALYLVCGERGFF

PTP-IA-2 612-636 (Q16849)

$|1: 1: \quad|:::::|/|:||: \mid:$

PTP-IA-2 839-856 (Q16849)

LVSEH IWCEDFLVRSFYL

$:|:: 1: 1::| 1 \quad:: \mid 1$

Insulin 25-41 (P01308)

FVNQHL- CGSHLVEALYL

PTP-IA-2 147-179 (Q16849)

TGSAPAAQHRLPQPPVGKGGAGASSSLSPLQAE

Insulin 51-83 (P01308)

PTP-IA-2 224-236 (Q16849)

1:: : ::| /: |: | | :::: $|1:||| 1: \mid$

TPKTRREAEDLQVGQVELGGGPGAGSLQPLALE

$: 1: 11 \mid 1:: 11:$

EGSPGMVSVGPLP

PTP-IA-2 165-179 (Q16849)

GGAGASSSLSPLQAE

Insulin 53-83 (P01308)

PTP-IA-2 538-565 (Q16849)

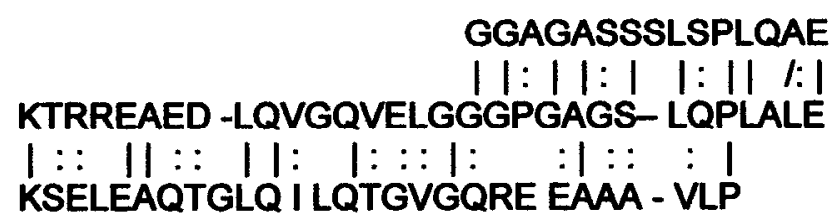

sequences from each of three patients. TCR 1,2 and 4 were from one patient [4]; TCR 8, 9, and 10 from a second patient [4] ; and TCR K2.4, K2.12, and K2.16 from a third [23]. TCR K2.12 and TCR 2 were highly homologous, so only the TCR 2 sequence was synthesized. Similarly TCR K2.16 and TCR 4 were highly homologous, so only TCR 4 was synthesized. Three of the TCR shared a common similarity (4, 8 and 9) so a single concensus sequence was synthesized. Notably, TCR K2.12 and TCR 10 are almost identical to TCR from multiple NOD mice [20, 23, 25] and similarities to TCR 1, 2, 8, 9, K2.4, and K2.16 are also evident with NOD TCR [25]. Thus, the interactions between the TCR sequences synthesized here are likely to be characteristic of diabetic and NOD TCR from multiple patients and diabetic animals. The HIV-related TCR were used as controls for this study.
UV Spectroscopy Study of TCR-Antigen Binding

Four sets of experimental tests were run. First, ultraviolet (UV) spectroscopy was used to determine whether the TCR sequences listed in Table $\mathbf{1}$ bind to insulin (Sigma-Aldrich), glucagon (Sigma-Aldrich), or either of the two peptides IR 105-118 and IR 897-915, derived from the insulin receptor (IR) as described above (see Table $\mathbf{1}$ for sequences). These hormone and IR peptides were dissolved as solutions of ca. $0.5 \mathrm{mM}$ in $\mathrm{pH} 7.4$ phosphate buffer (Fisher Scientific) and $50 \mu \mathrm{M}$ solutions were then made for use in spectroscopy. The TCR peptides were dissolved in the same buffer at 0.5 $\mathrm{mM}$ and then serially diluted eight times by thirds. $100 \mu \mathrm{l}$ of each TCR concentration plus $100 \mu$ l of buffer; mixtures of $100 \mu$ l of each hormone or IR peptide with $100 \mu$ l of buffer; and $100 \mu \mathrm{l}$ of each hormone or IR peptide with $100 \mu \mathrm{l}$ of 
each TCR concentration were made in a crystal 96-well plate and a complete spectrum from $190 \mathrm{~nm}$ to $250 \mathrm{~nm}$ of each well recorded on a Spectromax Plus spectrophotometer. Data were collected using SoftMax Pro 4.0 software. Every combination was done in duplicate and the results averaged. These curves were examined for the absorbance at which the greatest spectral shifts occurred (usually $205 \mathrm{~nm}$ ). The absorbance of a mixture of the hormone or IR peptide with TCR peptide was compared with the sum of the absorbances of the hormone or IR peptide (plus buffer) and TCR (plus buffer) and the differences plotted as a function of the concentration of the TCR peptide. A flat line resulted if there was no binding and an " $\mathrm{S}$ "-shaped curve if binding was evident. Binding constants were determined from the inflection point of the curves. In general, with the range of concentrations of peptides used here, this method is able to determine binding constants between about100 $\mathrm{nM}$ and $1 \mathrm{mM}$.

\section{UV Spectroscopy Study of TCR-TCR Binding}

UV spectroscopy was also used to determine whether any of the TCR bound to each other and the same protocol was used as above, holding one TCR at a constant concentration of about $50 \mu \mathrm{M}$ and varying the concentration of the other by thirds starting at $0.5 \mathrm{mM}$. All possible combinations of the TCR were tested holding each one constant and varying the others.

\section{ELISA Study of Antibody-TCR Binding}

A third set of experiments utilized an enzyme-linked immunoadsorption assay (ELISA) to test the ability of antibodies against human insulin (guinea pig, Biodesign K10264C), human glucagon (rabbit, Millipore, AB932), the alpha protein of the insulin receptor (rabbit, Biodesign, K54244R), the beta protein of the insulin receptor (mouse, Biodesign, K54241M), or antibody against the glucagon receptor (rabbit, Santa Cruz Biotechnology, sc-66912) to recognize any of the diabetic TCR peptides. Each TCR peptide was dissolved in buffer to produce a $50 \mu \mathrm{M}$ stock solution and $100 \mu \mathrm{l}$ were then added to an ELISA plate (Costar), incubated for an hour, and then triply washed with a $1 \%$ solution of TWEEN in phosphate buffer. $200 \mu \mathrm{l}$ of a $2 \%$ polyvinylalcohol (PVA) blocking agent in phosphate buffer was added to each well, incubated for an hour, and triply washed. $100 \mu \mathrm{l}$ of a 1:100 dilution of antibody was then added to each well, incubated for an hour, and triply washed. $100 \mu \mathrm{l}$ of a horse-radish-peroxidase (HRP) linked secondary antibody appropriate to the species of the test antibody (Chemicon) was then added to each well and incubated for an hour before being washed out. Finally, $100 \mu \mathrm{l}$ of ABTS single reagent (Chemicon) was added to each well, incubated for 30 minutes, and the plate read at $405 \mathrm{~nm}$ in a Spectromax scanning spectrometer. All combinations and controls were run in duplicate and the resulting values averaged.

\section{ELISA Study of Idiotype-Antiidiotype Antibody Binding}

Finally, the antibodies listed above were tested for binding to each other (i.e., for their ability form idiotypeantiidiotype pairs) using a double-antibody (DA) ELISA protocol [29, 33]. DA-ELISA is performed just as a standard ELISA is, but the antigen is replaced with a primary anti- body (plated in dilutions from 1/30 through 1/1,000,000 by thirds in $\mathrm{pH} 7.4$ phosphate buffer). The test antibody must be from a species other than that used as the primary antibody and is applied at 1/100 dilution. An enzyme-linked antibody against the test antibody species is then added (1:1000 dilution) and used as a reporter of the test antibody binding to the primary antibody. The primary and test antibodies must be from different species in order for the reporter antibody to be able to differentiate between them. Since many of the antibodies used above were derived from rabbits, an additional monoclonal antibody against the insulin receptor (mouse, Biodesign, E42365M) was substituted for rabbit anti-insulin receptor in some of the DA-ELISA studies in order to increase the number of combinations testable.

\section{Data Analsysis}

All data were analyzed and plotted using an Excel spreadsheet program.

\section{A Note on Insulin Receptor Numbering}

All IR sequences (P06213) are provided in the SwissProt numbering system (http://www.expasy.ch) that begins with the pre-pro sequence. Many papers on the IR use a numbering system that begins with the edited transcript and are thus have 27 amino acids subtracted from the number as compared with the SwissProt convention.

\section{RESULTS}

\section{Antigen Homologies.}

Many significant homologies were found between human PTP-IA-2 (islet cell antigen 512) and both insulin and the insulin receptor. Table $\mathbf{1}$ summarizes a few of these. Many more (dozens) were found but only a representative listing is made here. Most of the homologies between PTP-IA-2 and insulin are in the insulin A chain, and these homologies appear scattered throughout the entire islet cell antigen protein. A similarly large number of homologies was found between PTP-IA-2 and the insulin receptor, but only the four most significant of those related directly to the two insulinreceptor peptides (IR 93-113 and IR 897-916) used in the experimental studies carried out here are shown in Table 6. Notably, these homologies are similar to the insulin B chain as well [25].

\section{TCR-Antigen Binding}

Table 2 summarizes the fact that all of the diabetic TCR synthesized for this study mimic either insulin, glucagon or one of their receptors [25]. Table 3 and Fig. (2) show that six of these eight TCR also bind directly to insulin, glucagon, or peptides from the insulin receptor with affinities ranging between $15 \mu \mathrm{M}$ and $500 \mu \mathrm{M}$. Two of the eight TCR did not bind to any of the peptides tested, but may have affinity for glucagon receptor, which was not tested. Given the fact that insulin itself is a major target of autoimmunity in diabetes, it is notable that five of the TCR recognized insulin as an antigen with affinities in the low to mid-micromolar range and five of the TCR also recognized IR peptides with 100-200 $\mu \mathrm{M}$ affinity. It is also worth noting that these binding constants may be significantly higher than real TCR would dis- 
play, since real TCR have several degrees less thermodynamic freedom by being bound into membranes than do the freely rotating peptides used in these solution binding experiments. It is likely, therefore, that TCR in situ within the membranes of $\mathrm{T}$ cells would exhibit higher affinities for glucagon, insulin and the insulin receptor than are reported here.

\section{TCR-TCR Binding}

The same interpretative caveats apply to the results summarized in Table 4 and Fig. (3), which shows the affinities of the various TCR peptides for each other. Most of the TCR peptides from the diabetic patients bind to other TCR peptides from diabetic patients with low to mid-micromolar affinities as expected from the various complementarities of the proteins they mimic. Most of the TCR therefore bear some complementary (possibly idiotype-antiidiotype) relationship with each other. None of the TCR from diabetic patients bound with measurable affinity to any of the seven TCR sequences from HIV-infected patients.

\section{Antibody-TCR Binding}

Table 5 and Figs (4 and 5) demonstrate that all of the diabetic TCR peptides were recognized as antigens at low nanomolar affinities by either polyclonal antibody against insulin (six of eight), glucagon (five of eight), or the alpha subunit of the insulin receptor (six of eight). Four of the TCR were recognized to a measurable degree by all three antibodies although some of the binding was nearly micromolar. These data suggest a complex set of complementary (possibly idiotype-antiidiotype) relationships between TCR and antibodies in diabetes. Notably, however, no TCR was recognized by the polyclonal antibodies against the beta subunit of insulin or the glucagon receptor that were utilized in these experiments.

\section{Antibody-Antibody Binding}

Table 6 summarizes data showing that several of the antibodies used in these experiments recognize each other as complementary (possibly idiotype-antiidiotype) pairs. Polyclonal insulin antibody recognized a monoclonal insulin receptor antibody with mid-picomolar affinity, while polyclonal insulin antibody recognized polyclonal glucagon antibody with nanomolar affinity (see also [29]). Various other mid-nanomolar interactions were also observed between insulin receptor antibodies and either insulin or glucagon receptor antibodies, suggesting further antibody complementarities (Fig 6).

\section{Multiple Complementary (Possibly Idiotype-Antiidioty- pe) Pairs In Every T1DM Patient}

What is most notable about these results is that the TCR from each individual patient from which they were derived (TCRs 1, 2 and 4 for patient 1; TCRs 8, 9, and 10 for patient 2; and TCRs K2.4, K2.12, and K2.12 for patient 3) display at least one complete set of TCR-antigen, TCR-TCR, TCRantibody, and antibody-antibody interactions. For Patient 1 , a female, the interactions were between the TCR peptides and Ins, Ins Rec peptides; most of these TCR peptides acted as complements for each other; and the TCR peptides were

Table 2. Similarities between $T$ Cell Receptor (TCR) Sequences and Insulin, the Insulin Receptor, Glucagon, and the Glucagon Receptor. The TCR Designations Refer to the Annotations Used by the Authors who Originally Sequenced them (See Text for Sources). TCR 1, 2, and 4 were Sequenced from one T1DM Patient [4]; TCR 8, 9, and 10 from Another [4]; and K2.4, K2.12, and K2.14 from a Third [23]. Note that Some TCR have More than one Designation Because more Than One Patient had Either Identical or Very Similar Sequences. The Sequence in Bold is that which was Synthesized and Used in the Experiments Described here. Not Shown is the Further Fact that Many of these Sequences are Very Similar to TCR from NOD Mice [25]

TCR diabetic 1 (GLUC)

GLUCAGON 11-21

TCR diabetic 2, K2.16 (GR)

GLUC REC 187-199

TCR diabetic 4, K2.4 (IR)

INS REC $927-942$

TCR diabetic 8 (Ins, GR)

INSULIN 45-51

INSULIN 18-27

TCR diabetic 9 (Ins and GR) GR 440- 457

TCR diabetic 10 (IR)

INS REC 232-245

TCR diabetic K2.12 (IR)

GLUC REC 160-169

INSULIN 18-26

TCR diabetic 4,8,9 (Ins, IR, GR) INS REC 893-904
GLUC REC 464-473

\section{DSSIYLCSVEATRAD DYSKYLDSRRA}

CSAMYLCASSLAVIRTDTQY ASFVLKASSVLVI

SSLATSGGGSDTQY ATSLAGNGSWTEPTYF

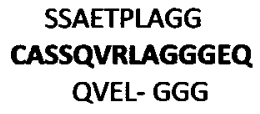

\section{ALYLVCGERG \\ SSLGQG - -ETEAFF SSSPGHGPPSKELQFGRG}

\section{GVY-CASRNLGLNTE GLC-CHSECLG- NCSQ CASSSDRLG-NQPQH}

\section{ALLL ALA ILG \\ ALYLVCGERG \\ DSALYLCASSLG DEELHLCKSRK}

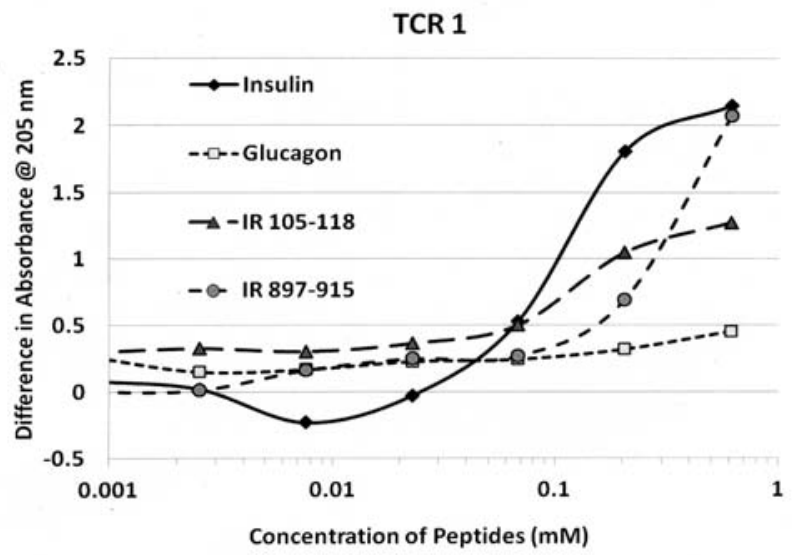

Fig. (2). UV spectroscopic study showing that T1DM-derived TCR1 peptide binds to insulin and a peptide from the alpha subunit of the insulin receptor with micromolar affinity. It also binds to glucagon somewhat more weakly, but not to a peptide from the beta subunit of the insulin receptor. Table 3 summarizes data derived from binding studies involving the rest of TCR described in Table 2. 


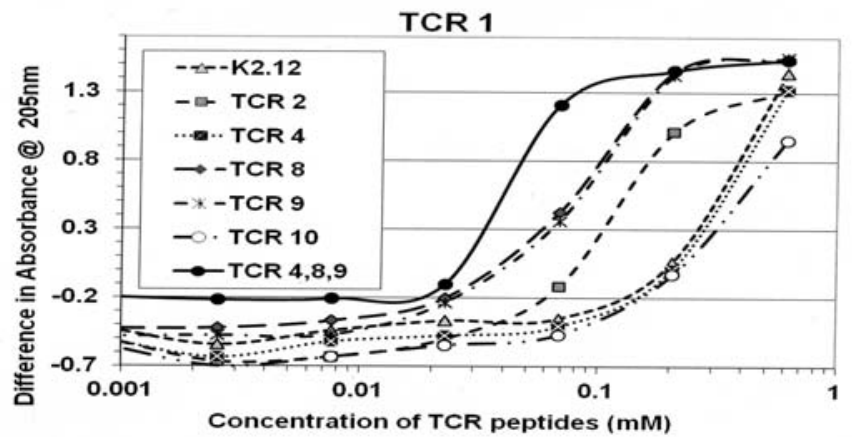

Fig. (3). UV spectroscopic study showing that T1DM-derived TCR1 peptide binds to other T1DM-derived TCR peptides. The TCRTCR affinities vary between low micromolar and unmeasurably small. Table $\mathbf{4}$ summarizes data derived from binding studies involving every possible combination of the rest of the TCR described in Table 2 . Table $\mathbf{4}$ also shows the results of binding studies of these diabetic TCR to TCR sequences from people with HIV infections. No TCR from an HIV positive individual bound to any of the diabetic TCR tested.

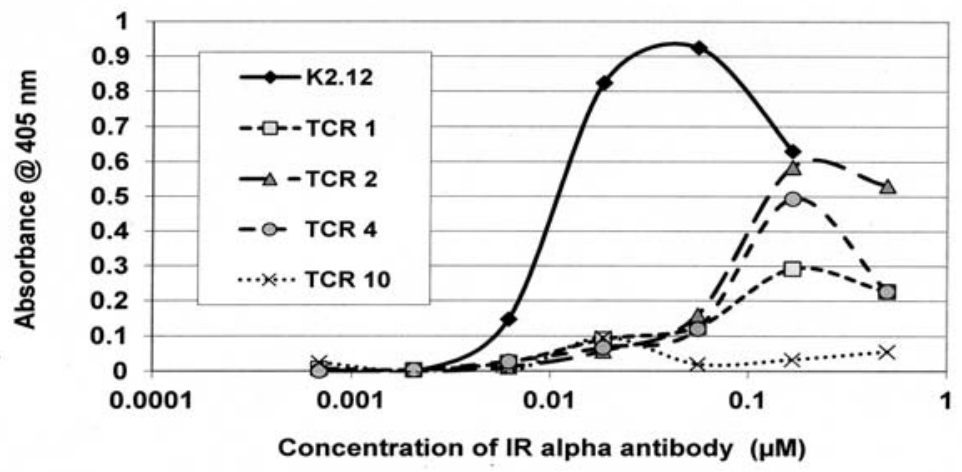

Fig. (4). Results of an ELISA study of antibody (rabbit) against the alpha subunit of the insulin receptor (IR) binding to the TCR described in Table 1. The IR antibody recognized TCR K2.12 with low nanomolar affinity, TCR 1, 2, 4 and 8 with mid-nanomolar affinity. Those TCR not shown were not recognized by the antibody at any concentration. Similar data for all other antibody-TCR combinations are summarized in Table $\mathbf{5}$.

Table 3. Binding of TCR to Insulin, Glucagon and Insulin-receptor Derived Peptides. UV Spectroscopic Study of the Binding of TCR from Table 2 to Insulin, Glucagon, and Two Insulin-like Peptides from the Insulin Receptor that have been Shown to have Nanomolar Affinity for Insulin [28]. Binding Constants are Expressed in Micromoles

\begin{tabular}{|c|c|c|c|c|}
\hline Binding Constants $(\mu \mathrm{M})$ & Insulin & Glucagon & Ins Rec $\alpha 105-118$ & Ins $\operatorname{Rec} \beta$ 897-915 \\
\hline TCR 4, K2.4 (IR) & 15 & $>1000$ & $>1000$ & $>1000$ \\
\hline TCR K2.12 (IR) & 75 & 120 & 120 & $>1000$ \\
\hline TCR 9 (Ins, GR) & 23 & 140 & 150 & 145 \\
\hline TCR 10 (IR) & 130 & 90 & 110 & 140 \\
\hline TCR 4,8,9 (Ins, IR, GR) & $>1000$ & $>1000$ & $>1000$ & $>1000$ \\
\hline
\end{tabular}

recognized by insulin antibody, insulin receptor antibody, and glucagon antibody; and several of these antibodies act as idiotype-antiidiotype pairs. A similar profile characterized patient 2, a male, whose TCR peptides recognized insulin, insulin receptor peptides, and glucagon; bound to each other as complementary pairs, and were recognized by antibody against insulin, insulin receptor, and glucagon, which also interacted as complementary pairs. Finally, Patient 3, another male, had TCR peptides that recognized insulin, insulin receptor peptides, and glucagons; these TCR interacted as complementary pairs; and were recognized by antibodies against insulin and glucagon antibodies, which are also a complementary pair. In sum, every patient displayed idiotypic recognition of diabetes-related antigens as well as all possible complementary (possibly idiotype-antiidiotype) permutations involving TCR and antibodies. 
Table 4. UV Spectroscopic Study of the Binding of TCR from Table 2 to Each Other and to Some TCR Induced by HIV Infection. The Similarities of Each Peptide to Insulin (INS), Glucagon (GLUC) or their Receptors (IR or GR) are Indicated in the Left-most and right-most Columns. Binding Constants are Expressed in Micromoles

\begin{tabular}{|c|c|c|c|c|c|c|c|}
\hline Binding Constants $(\mu \mathrm{M})$ & TCR 1 & TCR 2, K2.16 & TCR 4, K2.4 & TCR 8 & TCR 9 & TCR 10 & $\begin{array}{c}\text { TCR 4,8,9 (Ins, IR, } \\
\text { GR) }\end{array}$ \\
\hline TCR K2.12 (IR) & 90 & 130 & 250 & 110 & 110 & 110 & 180 \\
\hline TCR 1 (Gluc) & & 110 & 310 & 70 & 70 & 150 & 33 \\
\hline TCR 2, K2.16 (GR) & & & 230 & 220 & 330 & 120 & $>10,000$ \\
\hline TCR 8 (Ins, GR) & & & & & 400 & 270 & 200 \\
\hline TCR 9 (Ins, GR) & & & & & & $>1000$ & $>1000$ \\
\hline TCR 10 (IR) & & & & & & & 90 \\
\hline HIV TCR 1 CASSEELAGGSYNE & & & $>10,000$ & $>10,000$ & $>10,000$ & $>10,000$ & \\
\hline HIV TCR 4 CASSLELAKNI & & & $>10,000$ & $>10,000$ & & $>10,000$ & \\
\hline $\begin{array}{c}\text { HIV TCR } 5 \\
\text { CASSLWVTGGEQFF }\end{array}$ & & & $>10,000$ & $>10,000$ & & $>10,000$ & \\
\hline HIV TCR 7 CASSLTVSSYNEQ & & & & & & $>10,000$ & \\
\hline HIV TCR 8 RCASSSGANV & & & & & & $>10,000$ & \\
\hline
\end{tabular}

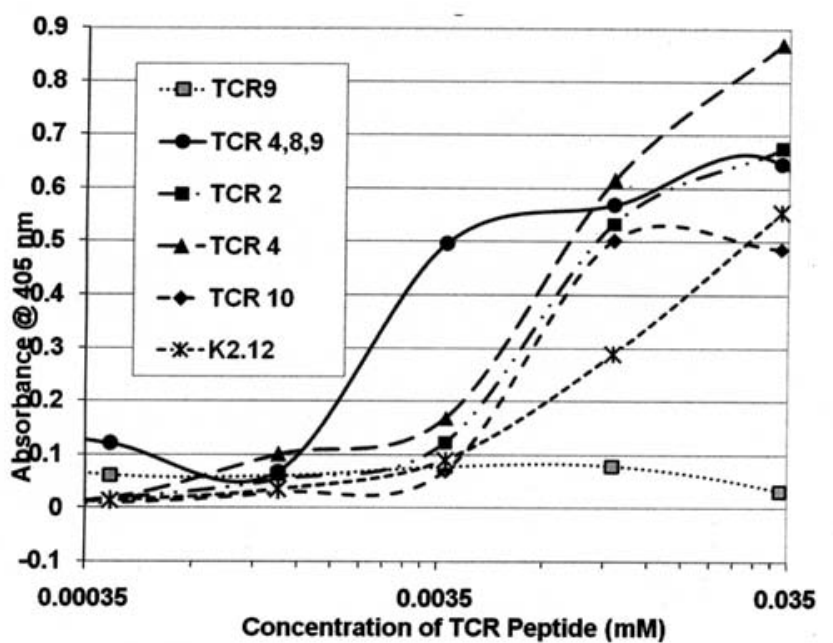

Fig. (5). Results of an ELISA study of antibody (guinea pig) against insulin binding to the TCR described in Table 1. The IR antibody recognized TCR 4,8,9 with sub-nanomolar affinity, TCR 2, 4 and 10 with mid-nanomolar affinity. Those TCR not shown were not recognized by the antibody at any concentration. Similar data for all other antibody-TCR combinations are summarized in Table 5.

\section{DISCUSSION AND CONCLUSIONS}

\section{Complementary (Possibly Idiotype-Antiidiotype) Net- works in Diabetes}

The current concensus is that T1DM is an autoimmune disease targeted at insulin and the pancreatic beta cells that produce it. One novel finding suggested by our data is that autoimmunity in T1DM may involve intra-immunological targets as well. TCR derived from human diabetic patients
[4, 20], and similar to those from NOD mice [20, 23, 25], recognize insulin, glucagon, and regions of the insulin receptor associated with insulin binding as antigens; these same TCR recognize other TCR from the same patients as antigens; these TCR are, in turn, recognized as antigens by antibodies to insulin, glucagon, and the insulin receptor; and finally these antibodies recognize each other as antigens. In sum, all of the theoretically possible permutations of complementary pairings that were predicted to be possible in Fig. 
Table 5. ELISA Study of Antibody Binding to the TCR Peptides Described in Table 1. The Antibodies Used were Against Insulin, Glucagon, the Alpha Subunit of the Insulin Receptor, the Beta Subunit of the Insulin Receptor, and the Glucagon Receptor. Binding Constants are Expressed in Nanomoles

\begin{tabular}{|c|c|c|c|c|c|}
\hline Binding Constants (nM) & Insulin Ab & Glucagon Ab & Ins Rec $\boldsymbol{\alpha}$ Ab & Ins Rec $\boldsymbol{\beta}$ Ab & Glucagon Rec Ab \\
\hline \hline TCR 1 (Gluc) & 220 & 110 & 24 & $>1000$ & $>1000$ \\
\hline TCR 2, K2.16 (GR) & 41 & 63 & 28 & $>1000$ & $>1000$ \\
\hline TCR 4, K2.4 (IR) & 55 & 99 & 3.8 & $>1000$ & $>1000$ \\
\hline TCR K2.12 (IR) & 550 & $>1000$ & 88 & $>1000$ \\
\hline TCR 8 (Ins, GR) & $>1000$ & $>1000$ & $>1000$ & $>1000$ \\
\hline TCR 9 (Ins, GR) & $>1000$ & 2.2 & $>1000$ & $>1000$ \\
\hline TCR 10 (IR) & 33 & $>1000$ & 300 & $>1000$ \\
\hline TCR 4,8,9 (Ins, IR, GR) & 12 & 5.0 & & $>1000$ \\
\hline
\end{tabular}

Table 6. Double Antibody ELISA Study of Idiotype-antiidiotype Interactions Among Antibodies Against Insulin, Glucagon, and their Receptors. These are the Same Antibodies as those Used in Deriving the Data Described in Table 4, with the Exception that a Monoclonal Antibody against Insulin Receptor was Also Employed so as to Expand the Range of Possible Antibody Combinations (See Text). These Data Expand Upon Those Previously Reported by Root-Bernstein and Dobbelstein [29]

\begin{tabular}{|c|c|c|c|c|c|}
\hline Binding Constants (nM) & Insulin Ab (Guinea Pig) & Ins Rec $\alpha$ Ab (Rabbit) & Ins Rec $\beta$ MAb & $\begin{array}{c}\text { Glucagon Rec Ab } \\
\text { (Rabbit) }\end{array}$ & $\begin{array}{c}\text { Glucagon Ab } \\
\text { (Rabbit) }\end{array}$ \\
\hline Insulin Ab (Guinea Pig) & & 440 & 38 & 88 & 1.1 \\
\hline Insulin Receptor MAb & 0.2 & $>1000$ & $>1000$ & $>1000$ & $>1000$ \\
\hline Insulin Receptor $\alpha \mathrm{Ab}$ (Rabbit) & 127 & & $>1000$ & 83 & $>1000$ \\
\hline
\end{tabular}

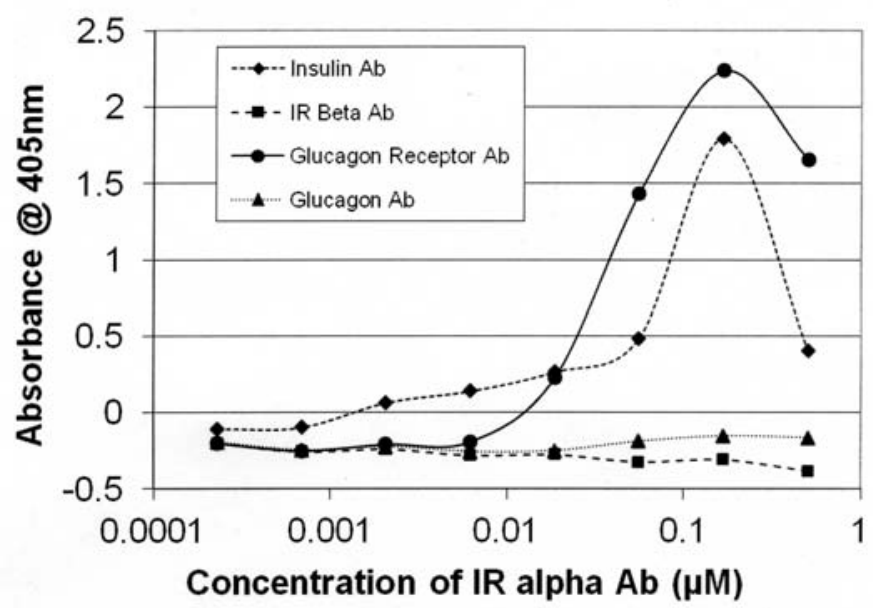

Fig. (6). Double antibody ELISA experiment showing that rabbit polyclonal antibody against the alpha subunit of the insulin receptor binds to antibody against insulin and rabbit polyclonal antibody against the glucagon receptor but not to antibody against the beta subunit of the insulin receptor or to antibody against glucagon. These results demonstrate that, just as insulin and glucagon are complementary [25, 29], as are their antibodies [25, 29], so are key antigenic determinants of their receptors (see Table 6).

(1) are manifested by the TCR and antibodies tested here. It will be interesting to see if additional manifestations of these interactions occur with specific peptides derived from the glucagon receptor and with other glucagon receptor antibodies as well.
We note that since performing the TCR syntheses, the TCR sequences of another T1DM patient has also been published [33]. Three of the seven sequences from this additional patient are similar to the sequences analyzed in this study (Table 7) and to those of NOD mice [4, 20, 23, 25]. Thus, it appears that a very high degree of constraint limits 
Table 7. Similarities between Three of the Seven Vß TCR Sequences Expanded from a Male Diabetic Patient in a Study Made Since the Experiments Performed here were Completed [33]. These Sequences Confirm that Similar TCR Sequences Appear to Characterize the Immune Response to T1DM in Both Human Patients and Mice [4, 20, 23, 25]

\begin{tabular}{|c|c|}
\hline V $\beta 7$ & CASSQVAGAGTGELFF \\
\hline TCR 8 (ins, GR) & CASSQVRLAGGGEQFF \\
\hline V $\beta 1$ & CASSVSTT - - - DTQYF \\
\hline TCR4, K2.4 (IR) & CASSLATSGGGSDTQYF \\
\hline V $\beta 11$ & CA- SSDP -GTQETQYF \\
\hline TCR K2.12 (IR) & CASSSDRLGNQ -PQHF \\
\hline
\end{tabular}

the TCR expression resulting in T1DM. The antigen mimicry expressed in the TCR by this additional T1DM patient suggest that he had TCR against the IR, insulin and perhaps the glucagon receptor.

\section{Insulin, Insulin Receptor, Glucagon and PTP-IA-2 as Integrated Targets of T1DM}

The data confirm that both insulin [1-9] and the insulin receptor [14-19] can be targets of autoimmunity in diabetes. The high degree of homology between PTP-IA-2 (islet cell autoantigen 512) and both insulin and the insulin receptor (Table 1) suggest that the TCR tested in this study are likely to recognize PTP-IA-2 as a possible antigen as well. Thus, TCR cross-reactivity and mimicry of autoantigens in T1DM may extend to islet cell targets other than insulin, including both IR and PTP-IA-2, in diabetes.

It is important to stress that while it is often asserted that IR autoantibodies result from an antiidiotype response to insulin autoantibodies [15, 17, 34-37], a number of studies have documented T1DM patients who presented first with autoantibodies to IR that later gave rise to autoantibodies to insulin $[16,18]$ and patients in which both sets of antibodies were present at diagnosis and prior to the initiation of insulin treatment $[14,38]$. Thus, it is possible for autoantibodies against IR to emerge before those against insulin, with them, or after them, making it difficult or impossible to conclude which, if either, is the antiidiotype to the other.

Since IR are expressed on most, if not all cells, there is also the possibility that anti-IR autoimmunity may extend beyond the pancreas. RNA expression patterns of the IR demonstrate that in addition to pancreas, IR are expressed at very high levels (approximately 50 fold higher than the levels found in most tissues) in ovaries, placenta and the adrenal cortex, and at about five or more fold typical levels in a variety of lymphocyte precursors, kidney, prostate and seminiferous tubules, retina and cerebellum [39]. These tissues and organs are, notably, those that are often most adversely affected during the progression of T1DM. Diabetic women typically have problems with their pregnancies; men with diabetes often experience fertility problems; adrenal insufficiency, kidney failure and retinopathy are common compli- cations of T1DM; and so is impaired immunity resulting in unusual susceptibility to infectious diseases such as pneumonias. Anti-IR autoantibodies have been implicated in poor perinatal outcomes for fetuses born to diabetic women [40, 41] and autoantibodies against retinal pericytes are associated with increased retinal damage in diabetes [42,43], but it is not known whether these anti-retinal antibodies are targeted to IR. Indeed, no studies appear to have been done thus far on the possibility that anti-IR antibodies have pathological consequences in other tissues or organs compromised during the progression of T1DM. We propose that anti-IR autoimmunity may help to explain the range of dysfunctions that accompany the primary attack on the pancreas during T1DM.

The data further suggest that glucagon may be a target of autoimmunity in some patients with T1DM, as has been previously reported in some clinical cases [30,31]. The novelty of the current study consists of demonstrating that the autoimmune response extends beyond antibodies to TCR sequences as well, and that these responses are not independent ones, but produce a highly integrated network of complementary interactions (Fig. 1).

\section{Results in Light of Competing Theories of Autoimmunity}

The experimental results we report here have different possible meanings depending on the theory of autoimmunity within which they are interpreted. Many theories of autoimmunity have been proposed over the past sixty years, including T-cell bypass, T-cell dysfunction, epitope drift, hyperinflammation, etc., but most theories agree that microbial triggers are involved in the induction of most naturally occurring autoimmune diseases. The two theories based on microbial triggering that have garnered the most evidential support are the molecular mimicry theory (MMT) [44] and the antiidiotype theory (AIT) [45].

MMT proposes that microbes have antigens that mimic host proteins and that - for unknown reasons that may be explained by T-cell bypass, epitope drift, etc. - sometimes the body produces antibodies and/or $\mathrm{T}$ cells that cross react with these host proteins (Fig. 7A). According to MMT, the primary, idiotype immune response cross-reacting with the self mimic is all that is necessary to provoke autoimmunity if that response somehow escapes regulation. MMT does not, therefore, predict or account for the sets of complementary antibody or TCR responses characterized here.

In contrast to MMT, AIT proposes that since microbes often use cellular receptors to target host tissues or organs, antiidiotype antibodies against viral antibodies will end up mimicking the microbe, thereby targeting its host tissue or organ (Fig. 7B). AIT is consistent with the complementarity between antibodies, between TCR and between antibodies and TCR characterized here, but assumes something that cannot be demonstrated here which is that this complementarity is due to the production of antiidiotype responses from primary idiotypic responses to a single antigen. AIT does not explain why some individuals produce self-reactive antiidiotype responses to any particular antigen when the vast majority of individuals do not. Moreover, according to AIT, the primary attack on insulin would have to be provoked by a primary immune response against something like glucagon 
or IR, resulting secondarily in the production of anti-idiotype antibodies against insulin. Thus, while AIT can account for the appearance of complementary immune responses characterized here as idiotype-antiidiotype networks, AIT requires that some microbe exist that mimics the IR or glucagon, so that the anti-insulin response is secondary (antiidiotypic) rather than primary (idiotypic) as all current literature does.

While there is little doubt that molecular mimics play a role in the development of autoimmunity, and that what appear to be antiidiotype antibodies have been reported in T1DM [14-18, 34, 38], neither MMT nor AIT explains why autoimmunity results so extremely rarely from any particular insulin- or insulin-receptor mimicking microbial infection, nor does either theory explain how immune system dysregulation results to permit autoimmunity. Moreover, attempts over 30 years to elicit T1DM (or any other autoimmune disease) in animals using purified molecular mimics (without adjuvants) or antiidiotype antibody production have universally failed. We have therefore proposed a theory based on antigenic complementarity that accounts for the data supporting both MMT and AIT while also accounting for their deficiencies. The antigenic complementarity theory (ACT) of autoimmunity proposes that autoimmunity follows from normal immune responses against concurrent infections characterized by the unusual property of displaying molecularly complementary antigens, at least one of which mimics a host protein. Simultaneous exposure to complementary anti-

A
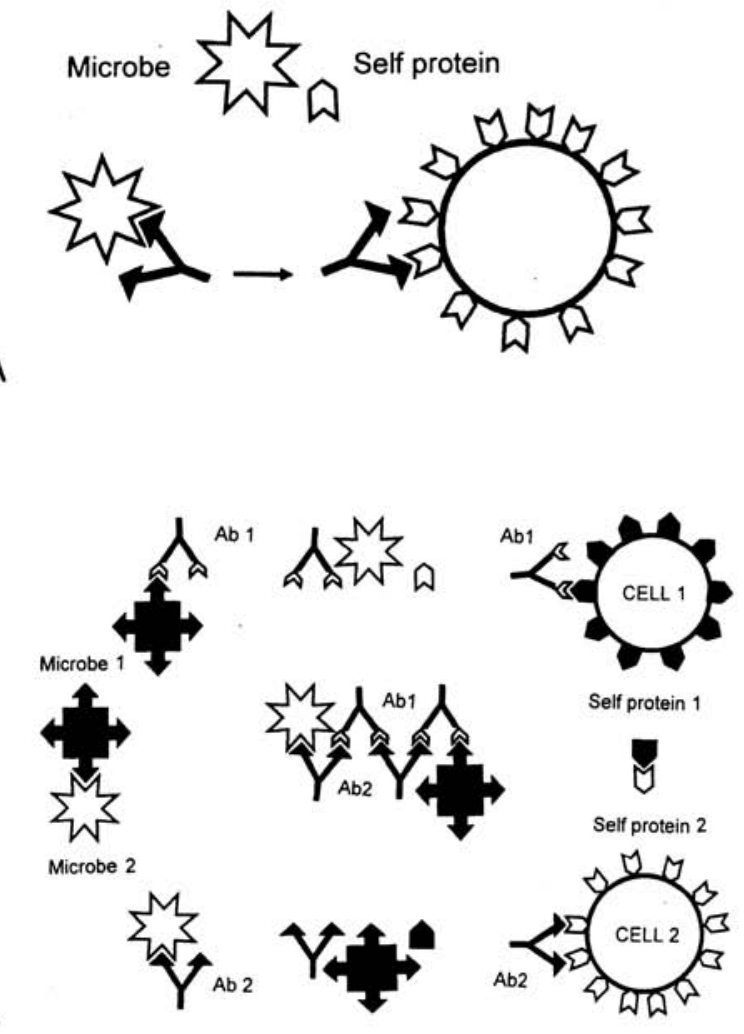

C

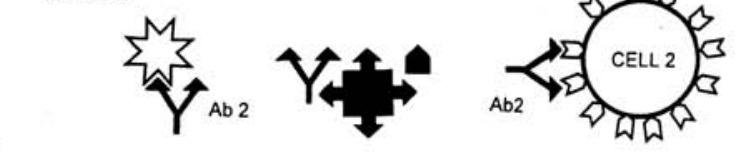

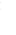

gens induces simultaneous, complementary immune responses expressed as antibodies (Fig. 7C), T cells or both (Fig. 7D). When both antibodies and TCR are activated, they will cross-react. These complementary immune responses appear to be idiotype-antiidiotype pairs, but actually arise simultaneously and independently of each other. Because the antigens are complementary, each immune response mimics one of the antigens. The mimicry between the antigens and the immune system responses to them results in the immune system losing the ability to distinguish self from nonself. Since at least one of the two antigens mimics a host protein as well, the loss of self-nonself discrimination permits an autoimmune response to proceed within the immune system itself as well as against a host tissue or organ. The constant presence of both host protein and, more importantly, complementary immune responses, ensures that the autoimmunity will be chronic because self-reinforcing. In sum, we propose that all autoimmune diseases are basically driven by the immune system attacking itself and only secondarily by the attack on a particular host tissue or organ. [25, 29, 46-49] ACT, like AIT, is also consistent with the complementary antibody and TCR interactions characterized here, but assumes that these complementary immune responses arise concurrently as independent responses to multiple, complementary antigens rather than as antiidiotype responses. Thus, ACT requires that there be both an insulin mimic and an IR or glucagon mimic to induce T1DM.

Fig. (7). A. A schematic drawing of the molecular mimicry theory (MMT). B. A schematic drawing of the antiidiotype theory of autoimmunity (AIT). C. A schematic drawing of the antigenic complementarity theory of autoimmunity (ACT) as applied to antibody production. D. ACT applied to TCR induction. ACT accounts for both molecular mimicry and the presence of antiidiotype antibodies in autoimmunity as well as complementary interactions among antibodies, TCR and BCR illustrated in Fig. (1), but not predicted by MMT or AIT. 
MMT, AIT, ACT and Complementary Immune Responses: Causes or Down-Regulators of Autoimmunity?

Several different, but not necessarily mutually exclusive, interpretations of the data presented above are possible depending on the theory from which one reasons. According to the Jerne network theory of immune regulation [50], antiidiotype antibodies are produced, in contrast to the AIT, as regulatory mechanisms for the idiotypic response [51, 52]. From this perspective, anti-TCR antibodies might also represent a regulatory mechanism invoked by the immune system to dampen the autoimmune response. Thus, Marchelonis [53] has reported that patients with rheumatoid arthritis and systemic lupus erythematosus have anti-TCR V beta autoantibodies that may limit the autoimmune reaction. The presence of complementary TCR in autoimmune patients with T1DM or other autoimmune diseases might similarly represent attempts by the immune system to control the autoimmune process. This possibility is enhanced by the fact that some of the TCR sequences listed in Table 2 mimic insulin, glucagon, and the insulin receptor. Perhaps the TCR that mimic insulin and insulin-receptor inhibit antibody that would otherwise attack hormonal and cellular targets. Such TCR may also target B-cells displaying insulin, glucagon, and insulin-receptor reactive B cell receptors, thereby downregulating production of insulin, glucagon, and insulinreceptor reactive antibodies. Notably, however, interpreting antibodies against TCR as regulatory requires that the antibodies be antiidiotypes, raising difficulties for both the MMT and AIT theories and opposing ACT.

\section{Complementary Antibodies (and TCR) as the Cause of Autoimmunity}

An alternative interpretation of complementary TCR and antibodies in autoimmunity arises from the ACT. We [25, 29, 46-49] and others [54-57] have suggested that the simultaneous activation of two sets of complementary T-cell clones (or antibodies) by complementary antigens (as might occur in a mixed infection) would trigger each clone to recognize not only its respective antigen, but also its complementary $\mathrm{T}$ cell, as targets. Such T-cell targeting of other T cells would create an immunological civil war that could lead to the kind of immunological confusion typifying autoimmune diseases, including loss of the self-nonself distinction [25, 29, 46-49]. Labeling one set of TCR and antibodies as primary and the complementary set as being "antiidiotypes" would then be misleading, since a key characteristic of antiidiotypes is that they arise significantly after the primary immune response and as a direct response to it. It has been demonstrated by many investigators that anti-IR antibodies are not secondary to the induction of insulin antibodies, but are present from the outset of T1DM [14, 16, 18, 38].

Whatever interpretation is put on our findings, it appears that even beyond complementary antibodies and antibodyTCR complementarity, there is TCR-TCR complementarity in autoimmune diseases as well. Many of the diabetic TCR synthesized in this study recognized others more or less specifically. Indeed, the promiscuity of the TCR for each other was much greater than that observed for antibody-antibody binding, TCR-antibody binding, TCR-antigen binding or antibody-antigen binding. While these promiscuous TCR-
TCR results may be surprising, they should be placed in the context of the recent discovery that a single TCR sequence can recognize more than a million different peptide sequences [58]. Such TCR promiscuity is certainly not predicted from the Burnet clonal selection theory, but may play a significant role in immune system regulation (and dysregulation) if, for example, Marchelonis's explanation of antiidiotype networks holds up. From the perspective of MMT and AIT, such TCR promiscuity would seem to be counterproductive, almost ensuring that every possible microbe would find a promiscuous TCR mimic. From the perspective of ACT, TCR promiscuity would, unfortunately make TCR complementarity in response to any set of complementary antigens highly likely.

It is also notable that the TCR complementarity seems to be constrained within the set of diabetic TCR, since none of the diabetic TCR tested against TCR from HIV infected patients produced measurable binding. This finding suggests that TCR complementarity is induced as a specific part of the autoimmune process.

\section{CONCLUSIONS}

In sum, the autoimmune response in diabetes is almost certainly more complex than is generally understood, and probably involves every possible set of complementary interactions that can occur between TCR, BCR and antibodies. The interactions appear, however, to be constrained to within this set of complementarities, rather than being randomly promiscuous. Targets include other TCR and antibodies and the insulin receptor in addition to the well-known targets of insulin and PTP-IA-2. Perversely, TCR not only target these proteins, but also mimic them. Thus, antigenic complementarity, such as that displayed between insulin and glucagon and between insulin and its receptor, also plays a fundamental role in the disease process by eliciting TCR that bind to other TCR as well. Understanding what triggers this set of complementary interactions, and how the set can be regulated, may provide new and important insights into the prevention and control of diabetes. Given Marchelonis's observation of antibody-TCR binding in other autoimmune diseases [53], it is likely that autoimmune diseases in general will turn out to display the antigen mimicry complicated by idiotype-antiidiotype network of TCR-BCR-antibody interactions that we have characterized here.

Our results lead to a number of novel predictions that are unique to ACT, differentiating it from MMT and AIT. By extrapolation from TCR-TCR complementarity in T1DM, one would also expect B-cell receptors to be targets of TCR and of antibodies in autoimmunity, though this prediction has yet to be tested experimentally. Any theory of autoimmunity may need to account for the entire range of possible idiotype-antiidiotype (or complementary antibody) interactions.

Another ACT-unique prediction follows from the observation that enteroviruses, especially coxsackie virus infections, are often associated with onset of T1DM [59-61] but that the timing of such infections is critical, sometimes leading to a protective effect [61]. Since MMT and AIT are based on single agent induction of autoimmunity, they cannot explain how timing can affect the outcome of infection. 
ACT can explain the timing issue, since ACT requires a complementary coinfection to induce autoimmunity. An uncomplicated enteroviral infection would protect against diabetes.

ACT also makes other unique predictions. In T1DM cases associated with coxsackie infection, we predict that some of the TCR will be complementary to coxsackie antigens and some will also mimic coxsackie antigens. Further, the TCR that mimic coxsackie antigens will target the antigens of an infectious agent molecularly complementary to coxsackie virus. The nature of this complementary infectious agent will be identifiable from the TCR sequences that target coxsackie virus antigens because the complementary infectious agent will mimic these TCR sequences. Finally, a combination of these complementary antigens will induce pairs of complementary antibody and TCR responses that will cause T1DM as they arise. These predictions are unique to ACT and therefore provide a test of the alternative interpretations of the data provided above.

\section{ACKNOWLEDGEMENTS}

This research was funded by a gift from Maurine Bernstein who had no input into the design of this study or its publication.

\section{CONFLICT OF INTERESTS}

The authors have no conflicts of interest.

\section{REFERENCES}

[1] Griffin A, Zhao CW, Wegmann KW, Hickley WF. Experimental autoimmune insulitis: induction by $\mathrm{T}$ lymphocytes specific for a peptide of proinsulin. Am J Pathol 1995; 147(3): 845-57.

[2] Schloot NC, Willemen S, Duinkerken G, de Vries RR, Roep BO. Cloned $\mathrm{T}$ cells from a recent onset IDDM patient reactive with insulin B-chain. J Autoimmun 1998; 11(2): 169-75.

[3] Narendran P, Williams AJ, Elsegood K, Leech NJ, Dayan CM. Humoral and cellular immune responses to proinsulin in adults with newly diagnosed type 1 diabetes. Diabetes Metab Res Rev 2003; 19(1): 52-9.

[4] Kent SC, Chen Y, Bregoll L, et al. Expanded T cells from pancreatic lymph nodes of type 1 diabetic subjects recognize an insulin epitope. Nature 2005; 435: 224-8.

[5] Nakayama M, Abiru N, Moriyama H, et al. Prime role for an insulin epitope in the development of type 1 diabetes in NOD mice. Nature 2005; 435(7039): 220-3.

[6] Nakayama M, Beilke JN, Jasinski JM, et al. Priming and effector dependence on insulin B:9-23 peptide in NOD islet autoimmunity. J Clin Invest 2007; 117(7): 1835-43.

[7] Pinkse GG, Tysma OH, Bergen CA, et al. Autoreactive CD8 T cells associated with beta cell destruction in type 1 diabetes. Proc Natl Acad Sci USA 2005; 102(51): 18425-30.

[8] Pinkse GG, Boitard C, Tree TI, Peakman M, Roep BO. HLA class I epitope discovery in type 1 diabetes: independent and reproducible identification of proinsulin epitopes of CD8 T cells--report of the IDS T Cell Workshop Committee. Ann NY Acad Sci 2006; 1079: $19-23$

[9] Jarchum I, Baker JC, Yamada T, et al. In vivo cytotoxicity of insulin-specific CD8+ T-cells in HLA-A*0201 transgenic NOD mice. Diabetes 2007; 56(10): 2551-60.

[10] Rabin DU, Pleasic SM, Shapiro JA, et al. Islet cell antigen 512 is a diabetes-specific islet autoantigen related to protein tyrosine phosphatases. J Immunol 1994; 152: 3183-8.

[11] Bonifacio E, Lampasona V, Genovese S, Ferrari M, Bosi E. Identification of protein tyrosine phosphotase-like IA-2 (islet cell antigen 512 ) as the insulin-dependent diabetes-related $37 / 40 \mathrm{~K}$ autoantigen and a target of islet-cell antibodies. J Immunol 1995; 155: 5419-26.
[12] Solimena M, Dirkx R Jr, Hermel J-M, et al. ICA 512, an autoantigen of type I diabetes, is an intrinsic membrane protein of neurosecretory granules. EMBO J 1996; 15: 2102-14.

[13] Honeyman MC, Stone NL, Harrison LC. T-cell epitopes in type 1 diabetes autoantigen tyrosine phosphatase IA-2: Potential for mimicry with rotavirus and other environmental agents. Mol Med 1998; 4: 2331-39.

[14] Batarseh H, Thompson RA, Odugbesan O, Barnett AH. Insulin receptor antibodies in diabetes mellitus. Clin Exp Immunol 1988; 71(1): 85-90.

[15] Blackard WG, Anderson JH, Mullinax F. Anti-Insulin receptor antibodies and diabetes. Ann Intern Med 1977; 86: 584-5.

[16] Elias D, Cohen IR, Schechter Y, Spirer Z, Golander A. Antibodies to insulin receptor followed by anti-idiotype antibodies to insulin in child with hypoglycemia. Diabetes 1987; 36: 348-54.

[17] Fonseca V, Khokher MA, Dandona P. Insulin receptor antibodies causing steroid responsive diabetes mellitus in a patient with myositis. Br Med J (Clin Res Ed) 1984; 288(6430): 1578.

[18] Maron R, Elias D, de Jongh BM, et al. Autoantibodies to the insulin receptor in juvenile onset insulin-dependent diabetes. Nature 1983; 303: 817-8.

[19] Baker FJ, Lee M, Chien Y-H, Davis MM. Restricted islet-cell reactive $\mathrm{T}$ cell repertoire of early pancreatic islet infiltrates in NOD mice. Proc Natl Acad Sci USA 2002; 99(14): 9374-9.

[20] Tikochinski Y, Elias D, Steeg C, et al. A shared TCR CDR3 sequence in NOD mouse autoimmune diabetes. Int Immunol 1999; 11(6): 951-6.

[21] Simone E, Daniel D, Schloot N, et al. T cell receptor restriction of diabetogenic autoimmune NOD T cells. Proc Natl Acad Sci USA 1997; 94: 2518-21.

[22] Galley KA, Danska JS. Per-islet infiltrates of young non-obese diabetic mice display restricted TCR beta-chain diversity. J Immunol 1995; 154: 2969-82.

[23] Durinovic-Bello I, Steinle A, Ziegler AG, Schendel DJ. HLA-DQrestricted, islet-specific T-cell clones of a type I diabetic patient: Tcell receptor sequence similarities to insulitis-inducing T-cells of nonobese diabetic mice. Diabetes 1994; 43: 1318-25.

[24] Candeias S, Katz J, Benoist C, Mathis D, Haskins K. Islet-specific T-cell clones from nonobese diabetic mice express heterogeneous T-cell receptors. Proc Natl Acad Sci USA 1991; 88: 6167-70.

[25] Root-Bernstein R. Autoreactive T-cell receptor (Vß/D/Jß) sequences in diabetes are homologous to insulin, glucagon, the insulin receptor, and the glucagon receptor. J Mol Recognit 2009; 22: 177-87.

[26] Root-Bernstein R. Molecular complementarity III. Molecular complementarity as the basis for peptide hormone evolution: a bioinformatic case study of insulin, glucagon, and gastrin. J Theor Biol 2002; 218: 71-84.

[27] Root-Bernstein R. Peptide self-aggregation and peptide complementarity as bases for the evolution of peptide receptors: a review. J Mol Recogn 2005; 18: 40-9.

[28] Root-Bernstein RS, Vonck J. Glucose binds to the insulin receptor affecting the mutual affinity of insulin for its receptor. Cell Mol Life Sci 2009; 66(16): 2721-32.

[29] Root-Bernstein RS, Dobbelstein C. Insulin binds to glucagon forming a complex that is hyper-antigenic and inducing complementary antibodies having an idiotype-antiidiotype relationship. Autoimmunity 2001; 33: 153-69.

[30] Fuchs U, von Dorsche HH, Ziegler M, Ambrosius H. Antiglucagon insulitis and A-cell hyperplasia of pancreatic islets. Z Mikrosk Anat Forsch 1988; 102(5): 829-32.

[31] Gergely A, Koranyl L, Halmos T, et al. Anti-glucagon antibodies in diabetes mellitus. Ann Immunol Hung 1973; 17: 231-3.

[32] Huang X, Miller W. A time-efficient, linear-space local similarity algorithm. Adv Appl Math 1991; 12: 337-57.

[33] Codina-Busqueta E, Scholz E, Munoz-Torres PM, et al. TCR bias of in vivo expanded $\mathrm{T}$ cells in pancreatic islets and spleen at the onset in human type 1 diabetes. J Immunol 2011; 186: 3787-97.

[34] Shoelson SE, Marshall S, Horikoshi H, KOlterman OG, Rubenstein $\mathrm{AH}$, Olefsky JM. Antiinsulin receptor antibodies in an insulindependent diabetic may arise as autoantiidiotypes. J Clin Endocrinol Metab 1986; 63: 56-61.

[35] Shechter YR, Maron D, Cohen IR. Autoantibodies to insulin receptor spontaneously develop as anti-idiotypes in mice immunized with insulin. Science 1982; 216: 542-4. 
[36] Shechter Y, Elias D, Maron R, Cohen IR. Mouse antibodies to the insulin receptor developing spontaneously as antiidiotypes: characterization of the antibodies. J Biol Chem 1985; 259: 6411-5.

[37] Elias D, Maron R, Cohen IR, Shechter Y. Mouse antibodies to the insulin receptor developing spontaneously as anti-idiotypes: effects on glucose homeostasis and the insulin receptor. J Biol Chem 1984; 259: 6416-9.

[38] Ludwig SM, Faiman C, Dean JH. Insulin and insulin-receptor autoantibodies in children with newly diagnosed IDDM before insulin therapy. Diabetes 1987; 36: 420-25.

[39] Biogps.org. INSR. Available at: http://biogps.org/\#goto=genereport \&id=3643 Accessed 13 Nov 2012.

[40] Poletaev AB, Gnedenko BB, Makarova AA, et al. Possible mechanisms of diabetic fetopathy. Hum Antibodies 2000; 9: 189-97.

[41] Portsenko AM, Budykina TS, Morozov SG, Rybakov AS, Gribova IE, Protsenko AN. Perinatal outcomes in pregnant women with diabetes mellitus and different level of autoantibodies to insulin and its receptors. Patol Fiziol Eksp Ter 2010; 2: 18-22.

[42] Li Y, Smith D, Li Q, et al. Antibody-mediated retinal pericyte injury: implications for diabetic retinopathy. Invest Ophthalmol Vis Sci 2012; 53(9): 5520-6

[43] Attawia MA, Nayak RC. Circulating antipericyte autoantibodies in diabetic retinopathy. Retina 1999; 19(5): 390-400.

[44] Fujinami RS, Oldstone MB. Molecular mimicry as a mechanism for virus-induced autoimmunity. Immunol Res 1989; 8(1): 3-15.

[45] Plotz PH. Autoantibodies are anti-idiotype antibodies to antiviral antibodies. Lancet 1983; 2(8354): 824-6.

[46] Root-Bernstein RS. Self, nonself, and the paradoxes of autoimmunity. In: Tauber AI, Ed. Organism and the Development of Self. Boston: Kluwer 1991; pp. 159-209.

[47] Root-Bernstein R. Antigenic complementarity in the induction of autoimmunity: a general theory and review. Autoimmun Rev 2007; 6(5): 272-7.

[48] Root-Bernstein RS, Couturier J. Antigenic complementarity in the origins of autoimmunity: a general theory illustrated with a case study of idiopathic thrombocytopenia purpura. Clin Develop Immunol 2006; 13: 49-65.
[49] Root-Bernstein RS, Vonck J, Podufaly A. Antigenic complementarity between coxsackie virus and streptococci in rheumatic heart disease and myocarditis. Autoimmunity 2009; 22(3): 177-87.

[50] Jerne NK. Towards a network theory of the immune system. Ann Immunol 1974; 125C(1-2): 373-89.

[51] Tzioufas Ag, Routsias JG. Idiotype, anti-idiotype network of autoantibodies. Pathogenetic considerations and clinical application. Autoimmun Rev 2010; 9: 631-3.

[52] Hampe CS. 2012. Protective role of anti-idiotypic antibodies in autoimmunity - lessons for type 1 diabetes. Autoimmunity 2012; 45: 320-31.

[53] Adelman MK, Schluter SF, Robey IF, Marchalonis JJ. Natural and autoantibodies to human T-cell receptor Vbeta segments: potential roles in immunomodulation. Crit Rev Immunol 2007; 27(3): 221-32.

[54] McGuire KL, Holmes DS. Role of complementary proteins in autoimmunity. Trends Immunol 2005; 26: 367-72.

[55] Pendergraft WF, $3^{\mathrm{RD}}$, Preston GA, Shah RR, et al. Autoimmunity is triggered by cPR-3 (105-201), a protein complementary to human autoantigen proteinase-3. Nat Med 2004; 10: 72-9.

[56] Pendergraft WF $3^{\text {rd }}$, Jennette JC, Ralk RJ, Preston GA. Autoantigen complementarity: a new theory implicating complementary proteins as initiators of autoimmune disease. J Mol Med 2005; 83: 1225.

[57] Preston GA, Pendergraft WF $3^{\text {rd }}$, Falk RJ. New insights that link microbes with the generation of antineutrophil cytoplasmic autoantibodies: the theory of autoantigen complementarity. Curr Opin Nephrol Hypertens 2005; 14(3): 217-22.

[58] Wooldridge L, Ekeruche-Makinde J, van den Berg HA, et al. A singl autoimmune $\mathrm{T}$ cell receptor recognizes more than a million different peptides. J Biol Chem 2012; 287: 1168-77.

[59] Ylipaasto P, Smura T, Gopalacharyulu P, et al. Enterovirusinduced gene expression profile is critical for human pancreatic islet destruction. Diabetologia 2012; 55(12): 3273-83.

[60] Rešić LS, Honkanen H, Nix WA, et al. Seroconversion to islet autoantibodies after enterovirus infection in early pregnancy. Viral Immunol 2012; 25(4): 254-61.

[61] Christen U, Bender C, von Herrath MG. Infection as a cause of type 1 diabetes? Curr Opin Rheumatol 2012; 24(4): 417-23.

(C) Root-Bernstein and Podufaly; Licensee Bentham Open.

This is an open access article licensed under the terms of the Creative Commons Attribution Non-Commercial License (http://creativecommons.org/licenses/by-nc/3.0/) which permits unrestricted, non-commercial use, distribution and reproduction in any medium, provided the work is properly cited. 